\title{
Exploiting Modeling Studies for Evaluating the Potential Antiviral Activities of some Clinically Approved Drugs and Herbal Materials Against SARS-CoV-2: Theoretical Studies Towards Hindering the Virus and Blocking the Human Cellular Receptor
}

\author{
Eslam M. Abbass ${ }^{\mathbf{1}}$, Ali Kh. Khali1 ${ }^{\mathbf{1}}$, Yousra Abdel-Mottaleb ${ }^{\mathbf{2}}$, and M. S. A. Abdel-Mottaleb $\mathbf{3}^{\mathbf{3}}$ \\ ${ }^{1}$ Organic Chemistry Labs, Department of Chemistry, Faculty of Science, Ain Shams University, \\ Abbassia, 11566 Cairo, Egypt \\ ${ }^{2}$ Department of Pharmacology, Toxicology, and Biochemistry, Faculty of Pharmacy, Future \\ University in Egypt (FUE), 11835 Cairo, Egypt \\ ${ }^{3}$ Computational Chemistry Lab, Department of Chemistry, Faculty of Science, Ain Shams \\ University, Abbassia, 11566 Cairo, Egypt
}

Corresponding author: m.s.abdelmottaleb@sci.asu.edu.eg

\begin{abstract}
Here, we theoretically modeled the binding interaction of the Sars-CoV2 (Spike protein) utilizing molecular docking with some potential repurposed antiviral medications and two botanical products (Curcumin and Quercetin). Molecular docking between the drugs and the Sars-CoV2 proteins reflecting the pure electrostatic forces and $\mathrm{H}$-bond formation is complemented with the DFT results that shed light on the electronic nature of the interactions. Moreover, DFT computations provide invaluable information about the drug reactivity indices calculated from the energies of the frontier orbitals. The DFT results indicate intermolecular electron donor-acceptor interaction besides the H-bond formation. Most of the considered medication molecules act as electron-sink candidates except EIDD-2801, the electron donor. The theoretical results show the high possibility of blocking the human cellular entry against Sare-Cov2 or weakening Sars-Cov2 activity due to the electronic donor-acceptor interactions. The findings are solely computational analysis and need to be corroborated by additional studies.
\end{abstract}

Keywords: Antiviral drugs; Reactivity indices; DFT, Molecular Docking; Curcumin; Quercetin

\section{Introduction}

Coronavirus 2019 (COVID-19) has become a life-threatening global concern in recent days. It causes illness and death in some patients, but no specific treatment is available. Severe acute respiratory syndrome coronavirus 2 (SARS-CoV-2), which causes coronavirus, has significantly impacted human health and socioeconomic status globally [1,2]. SARS-CoV2 is a positive-sense single-stranded RNA virus that belongs to the betacoronavirus genus, presumed to have zoonotic origins since it has high genetic similarity to the coronavirus RaTG13, isolated from bats [3]. 
Furthermore, SARS-CoV-2 is structurally described [4,5]. Morphologically, the virus consists of four structural proteins, namely Spike (S), envelope (E), membrane (M), and nucleocapsid (N), among which the former three are integral membrane proteins, and the latter remains complexed with its RNA genome. In addition, it comprises 9 or 10 accessory proteins $[6,7,8]$. The spike (S) glycoprotein is a critical component of viral infection. It adheres to the host cell's surface receptor, human angiotensin-converting enzyme 2 (ACE2), allowing viral cellular entry via endosome formation and plasma-membrane fusion $[9,10]$.

The spike subunits called S1 and S2 are responsible for binding with the host-cell receptor and membrane fusion, respectively [11,12]. Different variants have been detected but do not significantly influence the efficacy of the developed vaccines [13]. In other concise words, SARSCoV-2 is an RNA virus branded by crown-like spikes on the external surface [14,15]. Any SARS$\mathrm{CoV}-2$ virus infection and replication cycle step is a potential target for antiviral interference. The binding of the viral spike protein of SARS-CoV-2 to the human cell surface receptor ACE2 is a critical step during the entry into human cells, causing infection. Hence, cell entry inhibitors could be used to prevent the SARS-CoV-2 virus and reduce the progression of COVID-19 diseases by preventing virus particles from infecting human cells.

Endemic seasonal coronaviruses cause morbidity and mortality in a subset of patients, but no specific treatment is available. Here we investigate six drugs and two natural food supplements, promising antiviral medications for treating SARS-CoV-2 infection. This study evaluates the potential of repurposing the medicines for treating seasonal human coronavirus disorders.

Several drug-repositioning studies and compound evaluations have been conducted to discover novel antiviral drugs against SARS-CoV-2 utilizing experimental and theoretical/computational methodologies [16-18]. The drug-repurposing effort considered herein focuses primarily on agents known to be effective against RNA viruses, including SARS-CoV and MERS-CoV. Thus, we have selected the drugs mentioned hereafter:

- N-Hydroxy-5'-O-isobutyryl-3,4-dihydrocytidin (EIDD2801), N-Hydroxycytidin (Eidd2801 metabolite or EIDD-1931), also known as Molnupiravir. Both were found to be effective against COVID-19. Molnupiravir is an orally available antiviral drug candidate currently in phase III trials to treat patients with COVID-19. Molnupiravir increases the frequency of viral RNA mutations and impairs SARS-CoV-2 replication in animal models and humans. 
- Favipiravir (favilavir), RdRp is a purine nucleoside that acts as an alternate substrate leading to inaccurate viral RNA synthesis used in viral infections.

- New favipiravir derivative, (E )-N -(4-cyanobenzylidene)-6-fluoro-3-hydroxypyrazine-2carboxamide (cyanorona-20), as the first potent SARS-CoV-2 inhibitor with very high selectivity (209- and 45-fold more potent than favipiravir and remdesivir, respectively)[19].

- Remdesivir [20,21] is a nucleotide analog that may block viral nucleotide synthesis to stop viral replication (Ebola virus infection).

- Fluvoxamine compound demonstrating moderate or vigorous [Cytochrome P450 (CYP) is a hemeprotein that plays a crucial role in the metabolism of drugs and other xenobiotics] CYP inhibition by reversible or a combination of reversible plus time-dependent inhibition.

The current study aims to model, via molecular docking, the binding energy and types of interactions of the Sars-Cov2 protein and ACE2 in human bodies shown in sketch (1) with the aforementioned antiviral medications, some of which are potentially tested by pharmaceuticals companies and newly suggested candidates, including natural products. Searching for more potent natural anti-COVID19 drugs is very demanding.[22-27]. Medicinal plants, especially those employed in traditional Chinese medicine, have attracted significant attention because they include bioactive compounds that could be used to develop legal drugs against several diseases with no or minimal risks [28]. We have chosen Flavonoid quercetin, an antioxidant and signaling molecule, and an effective Zinc ionophore [29]. Moreover, Curcumin is a medical herb of a powerful antioxidant, anti-inflammatory [30], antimutagenic, antimicrobial [31,32], and anticancer properties [33].

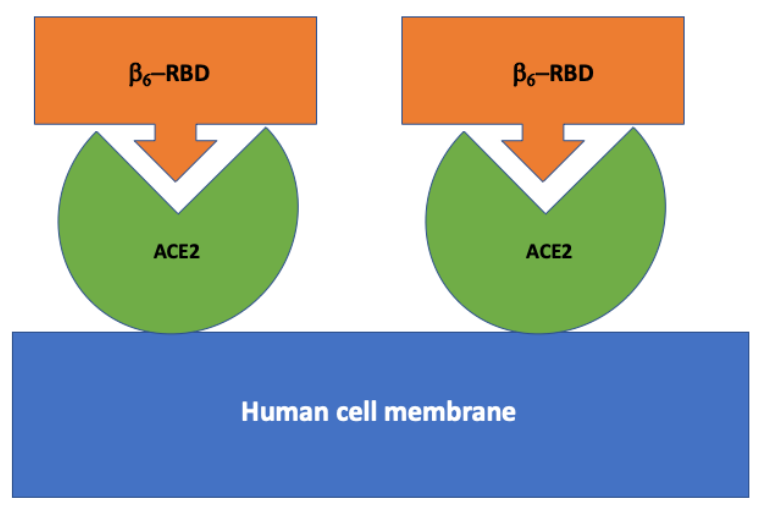

Sketch (1). A representation of the interaction of Sars-Cov2 protein with ACE2 in human bodies. 
We utilized two computational drug design methodologies to propose an efficient blocking and viable treatment for COVID-19. Moreover, molecular docking results are complemented with a simplified approach of selecting the presumed most reactive peptide-sequence $\left(\beta_{6}\right)[11,34]$ of the Spike of the S-Sars-Cov2 proteins using the DFT quantum chemical method to shed light on the electronic nature of the interactions utilizing a non-expensive way of drug trusting. Furthermore, DFT computations enable us to obtain invaluable information about the drug reactivity indices. Electronic and other weak bonding factors strengthen interaction forces by introducing multiple hydrogen bonds, covalent binding, additional van der Waals forces, or multivalent binding. Here we focus on the antiviral strategy of interfering with interactions involving host-guest sites to enhance the protective immune response against Sars-Cov2. However, although drugs targeting host proteins may be potentially cytotoxic or impact the human immune system, their appeal cannot be ignored [37]. Implementation of this medicinal chemistry strategy is expected to pave a direct way to discovering new drugs effective against current and future threats due to emerging and re-emerging viral pandemics.

\section{Methodology and Materials}

All the DFT calculations, including the optimization of ground-state geometry, are carried out using the Spartan 20 program. We applied the molecular mechanics' built-in Spartan 20 package to reach the interacting molecules' equilibrium geometry. We then applied single-point computations within the DFT theory to the molecular mechanically optimized equilibrium geometry using the long-range corrected hybrid density functionals, the wB97X-D functional [38], which includes empirical damped atom-atom dispersion corrections with 6-31G(d) basis set. The method used is efficient and cost-effective for seizing knowledge throughout biological hierarchies. We used the reaction field model for solvation (water) [the conductor-like polarizable continuum model (CPCM)], achieving a PCM (polarized continuum model) calculation [39].

We used MOE 2015.01 package [40] for docking the inhibitors to Sars-CoV2 protein and ACE2 that we obtained from Protein Data Bank (Crystal structure [6M0J]) [11]. We downloaded chemical structures of the ligands from ChemSpider structure search or as indicated in Table 1. To find effective drugs against S-Sars-Cov2, we searched for high-scoring value in docking studies involving different drugs.

The structures of the medication molecules are shown in Figure 1.

\section{Results and Discussion}

\subsection{Chemical structures of Drugs}


2D chemical structures of the chosen drugs are given in Scheme 1. Moreover, we include the ID of each drug in Table 1.

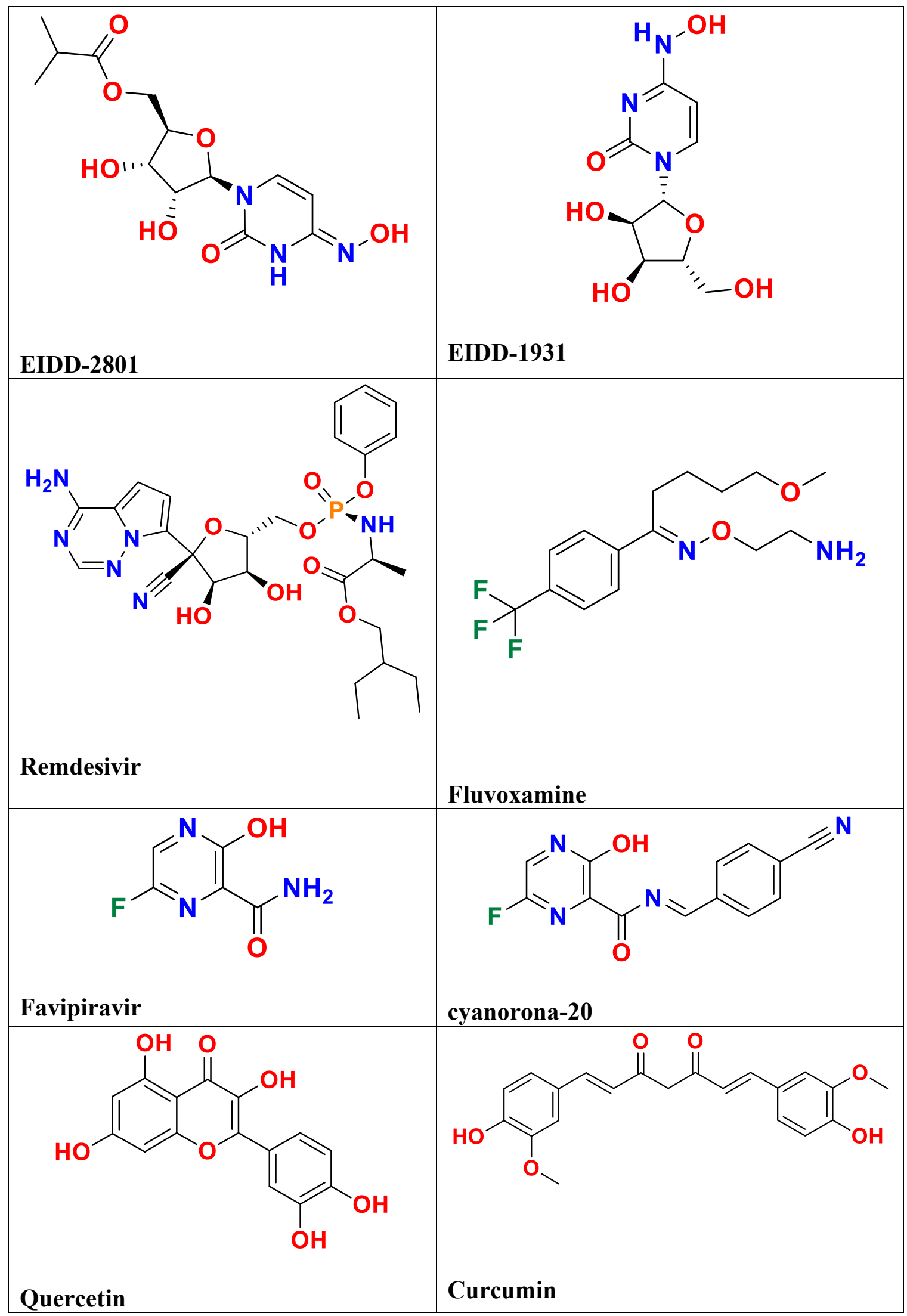

Scheme 1. 2D Chemical Structure of the medications 


\subsection{Electronic factors.}

DFT computational cost of large proteins is challenging and prohibitive. To overcome the computational barrier of applying DFT with the limited computational cost available, and to enable us to look at the electronic factors, we will simulate the chosen drugs' influence on the Spike protein of SARS-CoV-2, which was recently identified as the beta-sheet sequence $\left(\beta_{6}\right)$ that contains the topmost of the communicating protein strand SARS-CoV-2 that binds to a selected protein strand of ACE2 $[9,11,34]$.

Reactivity indices of the drug molecules will be first obtained from the energies of the frontier orbitals (EHOMO and ELUMO), by applying DFT method, according to the following equations:

$\mu=(E H O M O+E L U M O) / 2$,

$\eta=(E L U M O-E H O M O) / 2$

$\omega=\mu^{2} / 2 \eta$

HOMO and LUMO energies are valuable in analyzing the chemical potential $(\mu)$, hardness $(\eta)$, and electrophilicity $(\omega)$ that reveal the electronic donor-acceptor reactivity of the individual ligands and are crucial in assessing their reactivities toward proteins of the virus and the human receptor $[35,36]$. The results are summarized in Table (1). The more the ligand will be reactive, the more it will participate in electronic interactions and bond formation with protein. The electrophilicity index $\left(\omega=\mu^{2} /(2 * \eta)\right.$ measures a molecule's ability to act as an electron sink- the higher its value, the stronger the ligand's electron sink property. The electrophilicity index provides a magnitude of the energy stabilization of a molecule when it gains an extra amount of electron density during the interaction. The electrophilicity index comprises the tendency of an electrophile to earn an excessive amount of electron density, given by the chemical potential $\mu$ and the resistance of a molecule to exchange electron density during an interaction, provided by the hardness $\eta$. Therefore, a suitable electrophile is characterized by an excessive $\mu$ value and a little $\eta$ value. The electrophilicity index rendered a powerful apparatus for studying the reactivity of drug molecules [41]. $\omega$ values of all studied molecules except EIDD-2801 are higher than ACE2 and $\beta_{6}$ sheets. Thus, electron donor-acceptor affinity of the proteins - drugs increases with increasing the value of $\omega$. However, the electrophilicity fails to explain the orbital localization in the case of proteins interacting, as shown in Table 1 and Figures 1 . In this case, the hardness and chemical 
potential values are consistent with the donor-acceptor affinity visualized in Figure 1, where the HOMO - LUMO interactions reflect the donor-acceptor phenomenon of the proteins with each other. Figure 2 visualizes the electron acceptor property of the molnupiravir in the presence of both proteins. In other words, the medication is the electron sink agent that initially inhibits illness with covid-19. Other drugs behave similarly. This electronic situation leads us to assume a mechanism of blocking human cell entry or at least inhibits the electronic activity of the SarsCov2.

Table (1). Reactivity indices based on Frontier orbitals of free drugs and $\beta_{6}$ and ACE2 sequences

\begin{tabular}{|l|c|c|c|c|r|r|c|}
\hline Drug-free & Energy (au) & HOMO $(\mathrm{eV})$ & LUMO $(\mathrm{eV})$ & $\eta$ & $\mu$ & $\omega$ & ChemSpider ID/DOI \\
\hline EIDD-2801 & -1197.276 & -7.67 & 1.12 & 4.4 & -3.3 & 1.22 & $\underline{84400552}$ \\
\hline ACE2 & -2739.007 & -8.08 & 1.18 & 4.6 & -3.5 & 1.29 & Sheet Sequence [9]: HEGPLHK \\
\hline$\beta_{6}$ & -4195.229 & -7.81 & 1.00 & 4.4 & -3.4 & 1.32 & Sheet Sequence: YFPLQSYGFQ \\
\hline Remdesivir & -2321.072 & -8.02 & 0.78 & 4.4 & -3.6 & 1.49 & $\underline{58827832}$ \\
\hline EIDD-1931 & -1005.350 & -8.53 & 0.80 & 4.7 & -3.9 & 1.60 & $\underline{170635}$ \\
\hline Fluvoxamine & -1143.330 & -8.26 & 0.37 & 4.3 & -3.9 & 1.80 & $\underline{4481878}$ \\
\hline Quercetin & -1103.840 & -7.62 & 0.00 & 3.8 & -3.8 & 1.91 & $\underline{4444051}$ \\
\hline Curcumin & -1263.158 & -7.63 & -0.21 & 3.7 & -3.9 & 2.07 & $\underline{839564}$ \\
\hline Favipiravir & -607.308 & -8.90 & -0.25 & 4.3 & -4.6 & 2.42 & $\underline{431002}$ \\
\hline & & & & & & & $\underline{\text { https://doi.org/10.1007/s11696- }}$ \\
\hline
\end{tabular}

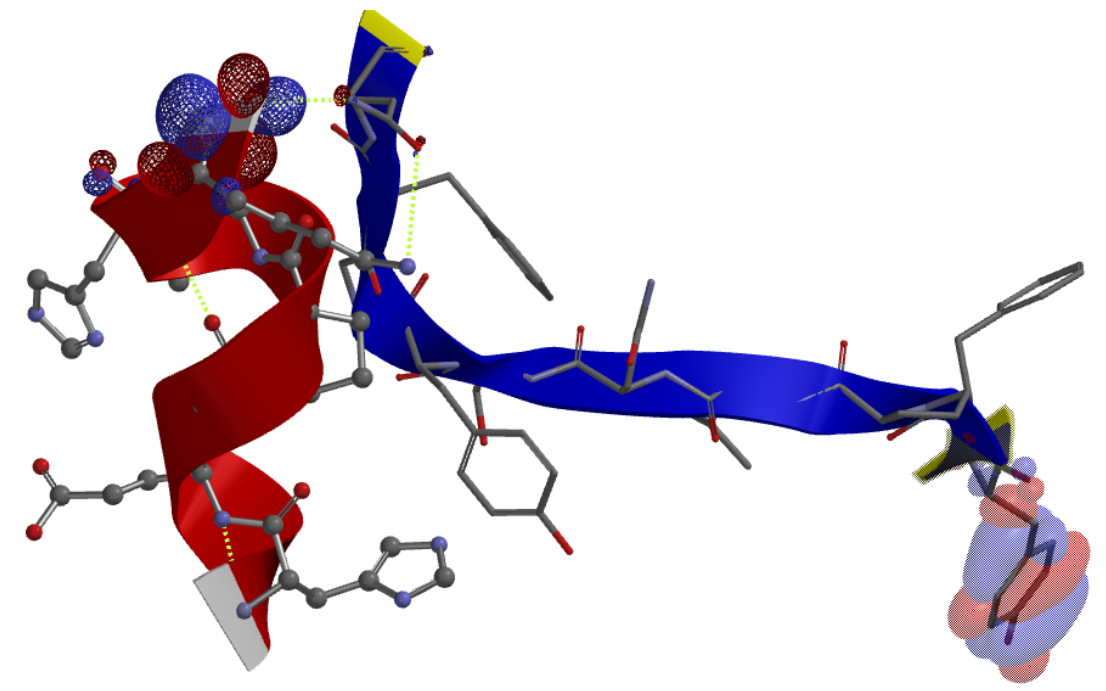

Figure 1. HOMO is wholly localized on the Sars-Cov2 (reactive peptide-sequence ( $\left.\beta_{6}\right)$ of the Spike of the S-Sars-Cov2 protein). The LUMO (dashed) is mainly from ACE2 Sheet (red ribbon). H-bonds are shown as dotted lines. 


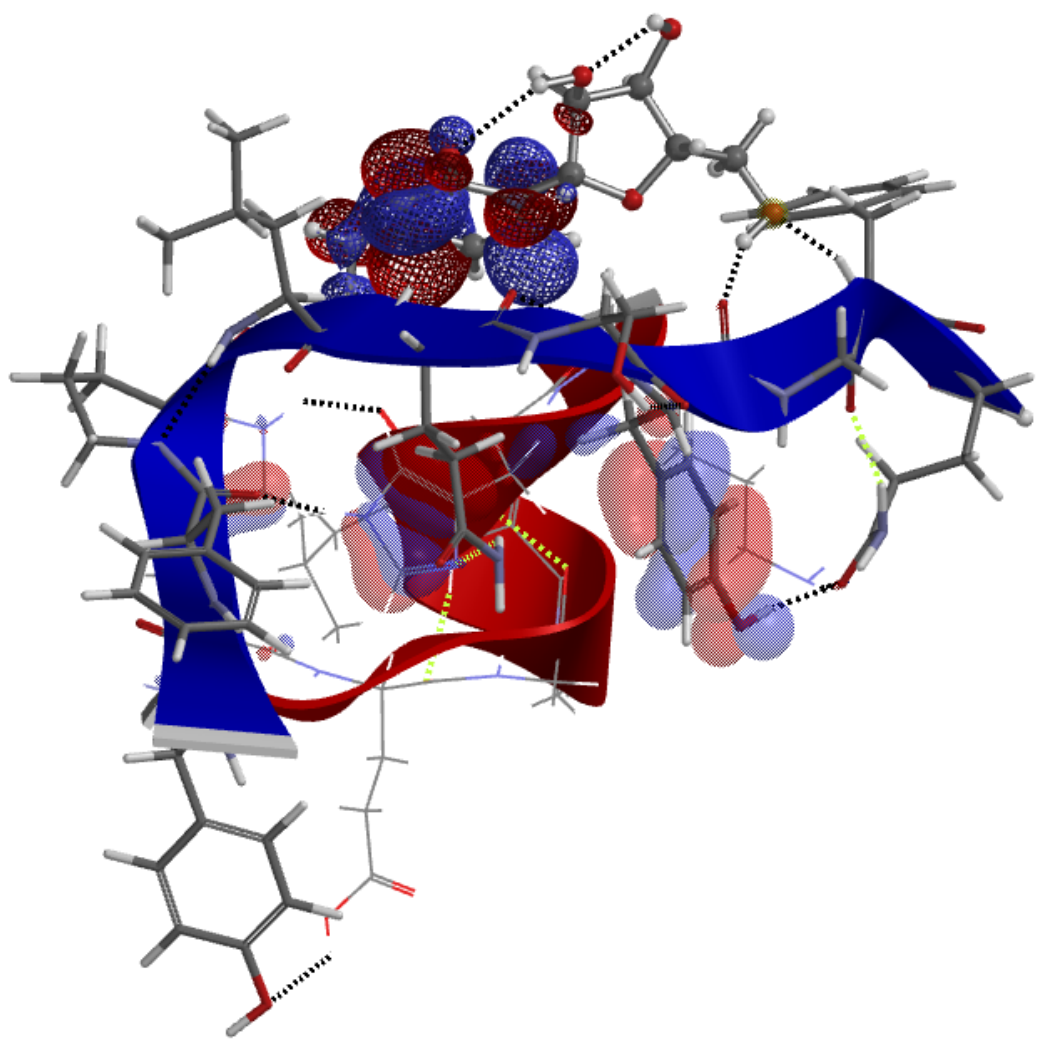

Figure 2. LUMO of the adduct Sars-Cov2 (reactive peptide-sequence ( $\left.\beta_{6}\right)$ of the Spike of the $S$ Sars-Cov2 proteins)-ACE2 Sheet and Molnupiravir (EIDD-1931) is wholly localized on the target medication (dashed orbital on spoke and ball representation of Molnupiravir). The HOMO (transparent) is mainly from b6 (Blue ribbon) with a minor contribution from ACE2 (Red ribbon). H-bonds are shown as dotted lines.

\subsection{Docking modelling}

To further widen the perspective, the current study modeled the binding interaction of the $\mathrm{S}$ protein and ACE2 in human bodies via molecular docking with these repurposed antiviral medications, including natural products. Our molecular docking score results showed (Table 2) the following general decreasing binding energy (in $\mathrm{kcal} / \mathrm{mol}$ ) of the drug with either SARS-Cov2 or ACE2 or the SARS-CoV2-ACE2 adduct

Remdesivir $>$ Curcumin $>$ Eidd-2801 $>$ Fluvoxamine $>$ Quercetin $>$ cyanorona-20 $>$ Eidd-1931 $>$ Favipiravir Figure 3 depicts the site where the Remdesivir drug molecule as an example reside in ACE2, Sars-Cov2 protein and ACE2-Sars-Cov2 proteins. 


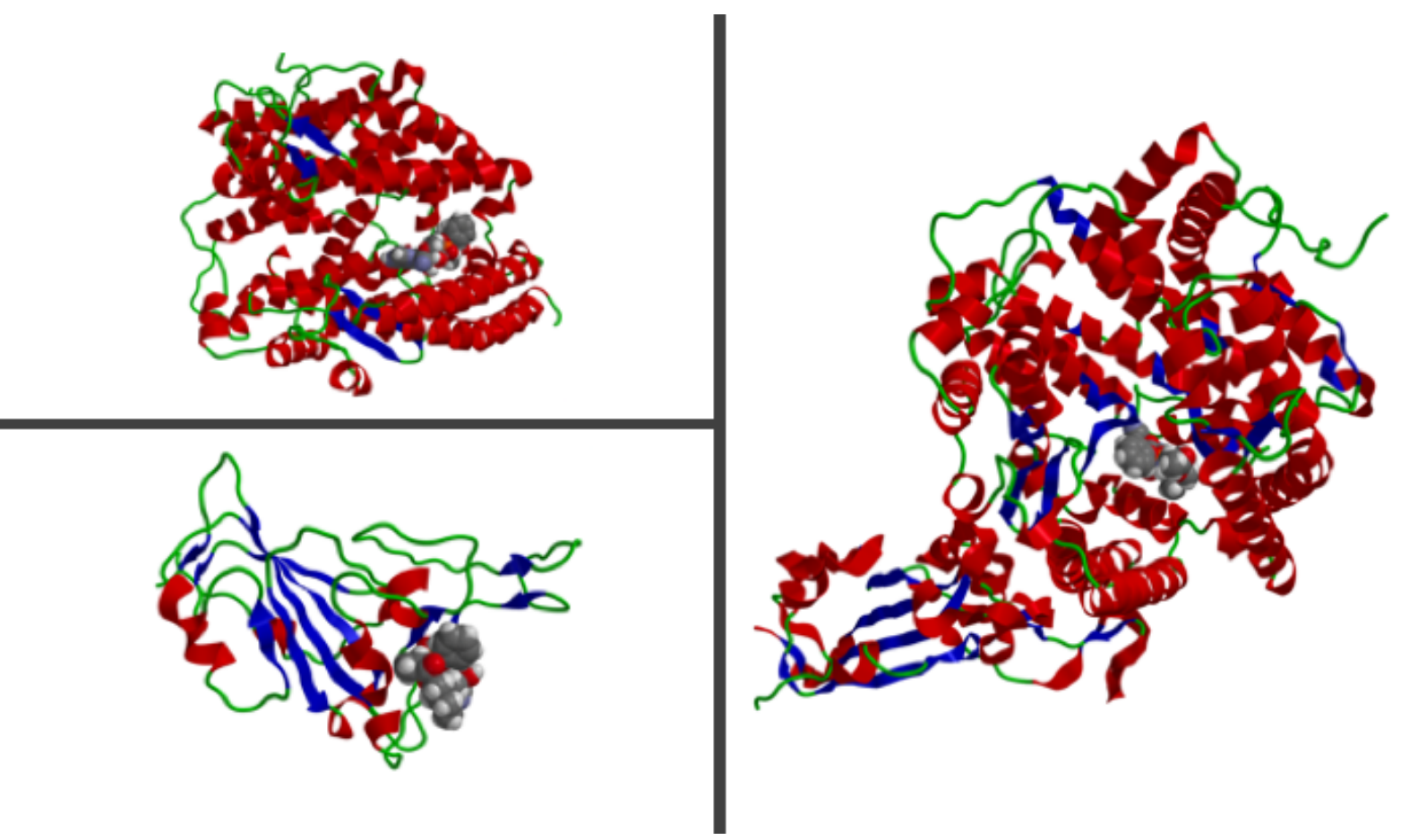

Figure 3. The most stable sites of Remdesivir (Space Filling model) in ACE2 (upper left pane), SARS-Cov2 (lower left pane), and the SARS-CoV2-ACE2 adduct (right-hand side).

The tested drugs reveal that the driving force of interactions is through specific forces such as $\mathrm{H}$ bond formation and the sum of the electrostatic and van der Waals energies (Table 3). The sum of all these interactions is approximated by a docking score, which represents the potentiality of binding in $\mathrm{kCal} / \mathrm{mol}$. The driving forces for these specific interactions in biological systems target complementarities between the shape and electrostatics of the binding location and the ligand or substrate. The effective site of noticeable contribution is with several amino acids of the $\beta_{6}$ antennae of the Spike of the S-Sars-Cov2 proteins as indicated in Figures 3 and 4 and Table 3. Other proposed drugs and the food supplements Curcumin and quercetin are assumed to behave towards the virus in a similar binding and electronic way.

A high docking score points to the higher potentiality of remdesivir and Merck medications in blocking S-Sars-Cov2 or ACE2, thus preventing or treating Covid-19 infections via binding with the individual proteins adduct ACE2 and S-Sars-Cov2.

Good binding affinity and reactivity response suggested that the studied medications can be promising drugs to inhibit the COVID-19 invasion. 
Table (2). Score values of the computationally predicted interactions

between SARS-CoV2 - Drug and ACE2 - Drug targets, and SARS-CoV2+ACE2 -drug giving the best binding mode score value representing binding free energy value, in $\mathrm{kcal} / \mathrm{mol}$

\begin{tabular}{|c|c|c|c|}
\hline \multirow{2}{*}{ Target } & \multicolumn{2}{|c|}{ Score } \\
\hline Remdesivir & Sars-Cov2 & ACE2 & Sars-Cov2 + ACE2 \\
\hline Curcumin & -6.51 & -7.84 & -9.55 \\
\hline Eidd-2801 & -5.67 & -7.23 & -7.53 \\
\hline Fluvoxamine & -5.54 & -6.89 & -6.72 \\
\hline Quercetin & -5.52 & -6.60 & -6.32 \\
\hline cyanorona-20 & -5.03 & -6.30 & -6.26 \\
\hline Eidd-1931 & -4.93 & -5.73 & -5.70 \\
\hline Favipiravir & -4.75 & -5.46 & -5.86 \\
\hline & & & -4.53 \\
\hline
\end{tabular}

As Table 3 shows, we can conclude the importance of some amino acids (highlighted) that belong to the antenna of the spike virus in binding with the target medication. Remdesivir, Molnupiravir (EIDD-2081), and Quercetin showed significant binding interactions with the antenna of the SARS-Cov2. Other drugs interact mainly with the ACE2 amino acids, blocking their receptor function. 
Table (3). Interaction types and characteristic values of the computationally predicted interactions between SARS- CoV2 and ACE2 and the drug targets

\begin{tabular}{|c|c|c|c|c|c|}
\hline Drug ACE2-Sars-CoV2 & Ligand & Receptor & $\begin{array}{c}\text { Type of } \\
\text { interaction }\end{array}$ & Interaction Distance & $\mathrm{E}(\mathrm{Kcal} / \mathrm{mol})$ \\
\hline Remdesivir & $\begin{array}{lr}\mathrm{N} & 63 \\
\mathrm{O} & 32 \\
\mathrm{~N} & 42 \\
\mathrm{O} & 45 \\
\mathrm{O} & 49 \\
\text { 5-ring } \\
\text { 6-ring } \\
\text { 6-ring }\end{array}$ & $\begin{array}{lcc}\text { O } & \text { ASN } & 210 \\
\text { NZ } & \text { LYS } & 562 \\
\text { N } & \text { TRP } & 566 \\
\text { CE } & \text { LYS } & 562 \\
\text { NZ } & \text { LYS } & 562 \\
\text { CA } & \text { VAL } & 209 \\
\text { CA } & \text { VAL } & 209 \\
\text { ND2 } & \text { ASN } & 210\end{array}$ & $\begin{array}{c}\text { H-donor } \\
\text { H-acceptor } \\
\text { H-acceptor } \\
\text { H-acceptor } \\
\text { H-acceptor } \\
\text { pi-H } \\
\text { pi-H } \\
\text { pi-H }\end{array}$ & $\begin{array}{l}2.87 \\
2.85 \\
3.06 \\
3.39 \\
3.01 \\
3.80 \\
4.19 \\
4.72\end{array}$ & $\begin{array}{l}-1.3 \\
-8.2 \\
-3.7 \\
-0.6 \\
-2.2 \\
-2.3 \\
-2.0 \\
-0.8\end{array}$ \\
\hline EIDD-2801 & $\begin{array}{lc}\text { C } & 8 \\
\text { O } & 36\end{array}$ & 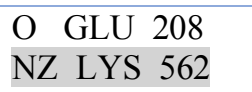 & $\begin{array}{c}\text { H-donor } \\
\text { H-acceptor }\end{array}$ & $\begin{array}{l}3.30 \\
2.86\end{array}$ & $\begin{array}{l}-1.0 \\
-3.7\end{array}$ \\
\hline Eidd-1931 & $\begin{array}{ll}\mathrm{O} & 2 \\
\mathrm{O} & 2 \\
\mathrm{O} & 8\end{array}$ & $\begin{array}{lll}\text { OE1 } & \text { GLU } 208 \\
\text { OH } & \text { TYR } 196 \\
\text { ND2 } & \text { ASN } 210\end{array}$ & $\begin{array}{c}\text { H-donor } \\
\text { H-acceptor H- } \\
\text { acceptor }\end{array}$ & $\begin{array}{l}2.80 \\
2.88 \\
3.08\end{array}$ & $\begin{array}{l}-3.7 \\
-1.8 \\
-2.5\end{array}$ \\
\hline Curcumin & $\begin{array}{l}\text { O } \quad 39 \\
\text { 6-ring }\end{array}$ & $\begin{array}{lrl}\text { O } & \text { ASN } & 210 \\
\text { CG1 } & \text { VAL } & 209\end{array}$ & $\begin{array}{l}\text { H-donor } \\
\text { pi-H }\end{array}$ & $\begin{array}{l}2.76 \\
4.02\end{array}$ & $\begin{array}{l}-2.5 \\
-0.7\end{array}$ \\
\hline $\begin{array}{c}\text { Favipiravir } \\
\text { cyanorona-20 }\end{array}$ & $\begin{array}{l}\text { 6-ring } \\
0 \quad 26 \\
\text { 6-ring }\end{array}$ & 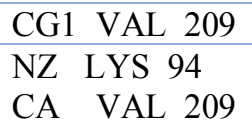 & $\begin{array}{c}\text { pi-H } \\
\text { H-acceptor } \\
\text { pi-H }\end{array}$ & $\begin{array}{l}3.95 \\
3.09 \\
3.88\end{array}$ & $\begin{array}{l}-0.7 \\
-7.3 \\
-1.3\end{array}$ \\
\hline Quercetin & $\begin{array}{ll}\mathrm{O} & 21 \\
\mathrm{O} & 28 \\
\mathrm{O} & 1 \\
\text { 6-ring } \\
\text { 6-ring }\end{array}$ & $\begin{array}{lll}\text { O } & \text { GLU } & 564 \\
\text { O } & \text { ALA } & 396 \\
\text { ND2 } & \text { ASN } & 210 \\
\text { CB } & \text { GLU } & 208 \\
\text { CB } & \text { GLU } & 208\end{array}$ & $\begin{array}{c}\text { H-donor } \\
\text { H-donor } \\
\text { H-acceptor } \\
\text { pi-H } \\
\text { pi-H }\end{array}$ & $\begin{array}{l}2.77 \\
2.73 \\
3.45 \\
4.38 \\
3.94\end{array}$ & $\begin{array}{l}-1.0 \\
-3.8 \\
-0.7 \\
-0.7 \\
-0.8\end{array}$ \\
\hline Fluvoxamine & $\mathrm{N} 1$ & NZ $\quad$ LYS 94 & H-acceptor & 3.01 & -4.9 \\
\hline
\end{tabular}




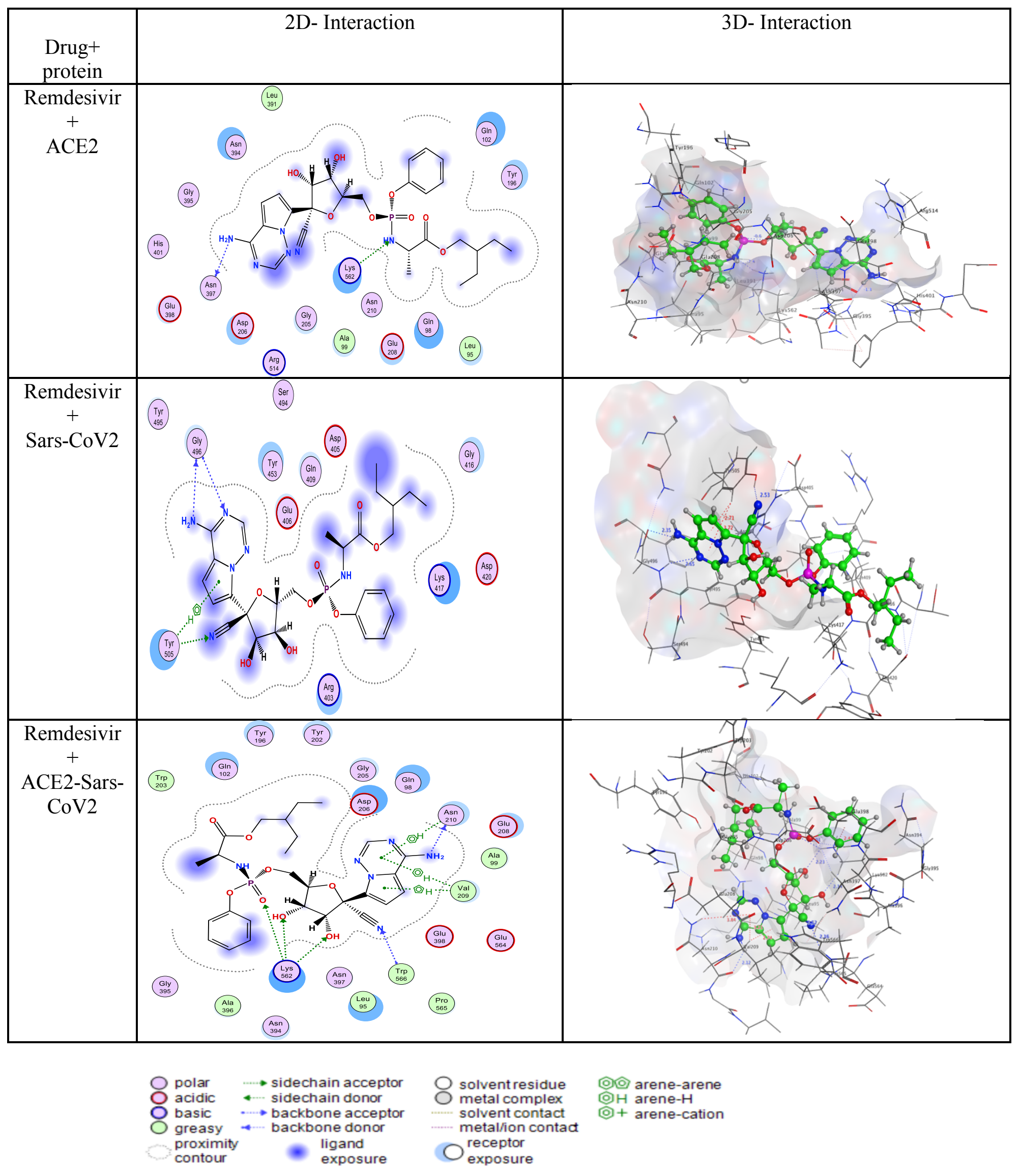

Figure 4. 2D and 3D representation of the Drug/Proteins Interactions. 


\section{Conclusion}

The current study modeled the binding interaction of the S protein and ACE2 in human bodies via molecular docking with some well-known repurposed antiviral medications, including natural products. We utilized two computational drug design methodologies to identify the origins of the interactions between the drugs and the Sars-CoV2 proteins. Molecular docking results are complemented with a simplified approach of selecting presumed reactive peptide-sequence $\left(\beta_{6}\right)$ of the Spike of the S-Sars-Cov2 proteins using the DFT quantum chemical method to shed light on the electronic nature of the interactions utilizing a non-expensive way of drug trusting. Moreover, DFT computations provide invaluable information about the drug reactivity indices correlated with the drug's electron donor-acceptor characteristics and SARS-Cov2 or ACE2. The results indicate intermolecular electron donor-acceptor interaction besides the H-bond formation, where most medications act as electron-sink candidates. Our molecular docking results showed that most of the tested drugs reveal that the driving force of interactions is through specific forces such as $\mathrm{H}$ bond formation and the sum of the electrostatic and van der Waals energies. The driving forces for these interactions in biological systems target complementarities between the shape and electrostatics of the binding location and the ligand or substrate. The effective site found is with several amino acids of the $\beta_{6}$ antennae of the Spike of the S-Sars-Cov2 proteins. The results show the high possibility of blocking the human cellular entry against Sare-Cov2 (through ACE2-Drug blockers) or weakening Sars-Cov2 activity. Frontier molecular orbitals of the drug-protein indicate that most of the considered drug molecules act as electron-sink candidates except EIDD-2801, which acts as the electron donor. The results show the high possibility of blocking the human cellular entry against Sare-Cov2 (through ACE2-Drug blockers) or weakening Sars-Cov2 activity. The findings are solely computational analysis and need to be supported by additional clinical studies. Moreover, the results of both computational methods applied, and the simplifications assumed in the case of DFT application are consistent to a great extent. 


\section{References}

1. C.C. Lai, T.P. Shih, W.C. Ko, H.J.Tang, P.R. Hsueh, Int. J. Antimicrob. Agents, 2020, 55, 105924.

2. T.E. Tallie, S.G. Tumilaar, T.J. Niode, F. Fatimawali, B.J. Kepel, R. Idroes, Y. Effendi, S.A. Sakib, T.B. Emran, Scientifica, 2020, 2020, 6307457.

3. M. Tahir Ul Qamar, S. M. Alqahtani, M. A. Alamri, L.-L. Chen, J. Pharm. Anal., 2020, 10, 313-319

4. K. Sharun, R. Tiwari, K. Dhama, T.B. Emran, A.A. Rabban, A. Al Mutair, Hum. Vaccines Immunother, 2021, 17, 1-4.

5. M. Romano, A. Ruggiero, F. Squeglia, G. Maga, R. Berisio, Cells, 2020, 9, 1267.

6. K. Khairan, R. Idroes, T.E. Tallie, M.J. Nasim, C. Jacob, Curr. Nutr. Food Sci., 2021, 17, 621633.

7. A. Rakib, P. Arkajyoti, N.C. Uddin, S.A. Sami, S.K. Baral, M. Majumder, A.M. Tareq, M.N. Amin, A. Shahriar, Z. Uddin, Molecules, 2020, 25, 3936.

8. R. Yadav, J.K. Chaudhary, N. Jain, P.K. Chaudhary, S. Khanra, P. Dhamija, A. Sharma, A. Kumar, S. Hadu, Cells. 2021, 10, 821.

9. W. Li, M.J. Moore, N. Vasilieva, J. Sui, S.K. Wong, M.A. Berne, M. Somasundaran, J.L. Sullivan, K. Luzuriaga, T.C. Greenough, Nature, 2003, 426, 450-454.

10. X. Ou, Y. Liu, X. Lei, P. Li, D. Mi, L. Ren, L. Guo, R. Guo, T. Chen, J. Hu, Nat. Commun., 2020, 11, 1-12.

11. J. Lan, J. Ge, J. Yu, Nature, 2020, 581, 215-220.

12. A.M. Rabie, Chem. Pap., 2021, 75, 4669-4685.

13. C. Laffeber, K. de Koning, R. Kanaar, J.H.G. Lebbink, J. Mol. Biol., 2021, 433, 167058.

14. M. Tahir ul Qamar, S. M. Alqahtani, M. A. Alamri, L. L. Chen, J. Pharm. Anal., 2020, 10, 313-319.

15. S. Jiang, C. Hillyer, L. Du, Trends Immunol., 2020, 41, 355-359.

16. A. Rakib, Z. Nain, M.A. Islam, S.A. Sami, S. Mahmud, A. Islam, S. Ahmed, A.B.F. Siddiqui, S.M.O.F. Babu, P. Hossain, Brief. Bioinform., 2021, 22, 1476-1498.

17. M. Dutta, A.M. Tareq, A. Rakib, S. Mahmud, S.A. Sami, J. Mallick, M.N. Islam, M. Majumder, M.Z. Uddin, A. Alsubaie, Biology, 2021, 10, 789.

18. K.H. Chowdhury, R. Chowdhury, S. Mahmud, A.M. Tareq, N.B. Hanif, N. Banu, A.S.M. Reza, T.B. Emran, J. Simal-Gandara, Biology, 2021, 10, 2.

19. D. Guo, Virol. Sin., 2020, 35(3), 253-255.

20. T. P.Sheahan, A. C. Sims, S. R. Leist, A. Schafer, J. Won, A. J. Brown, S. A. Montgomery, A. Hogg, D. Babusis, M. O. Clarke, J. E. Spahn, L. Bauer, S. Sellers, D. Porter, J. Y. Feng, T. Cihlar, R. Jordan, M. R. Denison, R. S. Baric, Nat. Commun., 2020, 11, 222.

21. M. Wang, R. Cao, L. Zhang, X. Yang, J. Liu, M. Xu, Z. Shi, Z. Hu, W. Zhong, G. Xiao, Cell Res., 2020, 30, 269.

22. D. S. Moirangthem, L. Surbala, Curr. Drug Targets, 2021, 22, 1346-1356.

23. V. C. Yan, F. L. Muller, ACS Med. Chem. Lett., 2020, 11, 1361-1366. 
24. L. Brunotte, S. Zheng, A. Mecate-Zambrano, J. Tang, S. Ludwig, U. Rescher, S. Schloer, Pharmaceutics., 2021, 13, 1400.

25. Q. Cai, M. Yang, D. Liu, J. Chen, D. Shu, J. Xia, X. Liao, Y. Gu, Q. Cai, Y. Yang, C. Shen, X. Li, L. Peng, D. Huang, J. Zhang, S. Zhang, F. Wang, J. Liu, L. Chen, S. Chen, Z. Wang, Z. Zhang, R. Cao, W. Zhong, Y. Liu, L. Liu, Engineering, 2020, 6, 1192-1198.

26. A. M. Rabie, Chem. Pap. 2021, 75, 4669-4685.

27. A. M. Rabie, Int. Immunopharmacol, 2021, 98, 107831.

28. M. Tahir ul Qamar, A. Maryam, I. Muneer, Sci. Rep., 2019, 9, 1-16.

29. H. Dabbagh-Bazarbachi, G. Clergeaud, I. M. Quesada, M. Ortiz, C. K. O’Sullivan, J. B. Fern.ndez-Larrea, J. Agric. Food Chem., 2014, 62, 8085-8093

30. M.L. Lestari, G. Indrayanto, Excip. Relat. Methodol., 2014. 39,113-204.

31. G. B. Mahady, S. L. Pendland, G. Yun, Z. Z. Lu, Anticancer Res., 2002, 22, 4179-4181.

32. R. C. Reddy, P. G. Vatsala, V. G. Keshamouni, G. Padmanaban, P. N. Rangarajan, Biochem. Biophys. Res. Commun., 2005, 326, 472-474.

33. L. Vera-Ramirez, P. Perez-Lopez, A. Varela-Lopez, M. Ramirez-Tortosa, M. Battino, J.L. Quiles, Biofactors, 2013, 39, 88-100.

34. M. S. A. Abdel-Mottaleb, Y. Abdel-Mottaleb, Egypt. J. Chem., 2021, 64, 989 - 996.

35. I. Fleming, John Wiley and Sons, 1976, 320, 879-880.

36. F. Zielinski, Chem. Phys. Lett., 2012, 527, 67-72.

37. Y. Ma, E. Frutos-Beltrán, D. Kang, C. Pannecouque, E. D. Clercq, L. Menéndez-Arias, X. Liu, P. Zhan, Chem. Soc. Rev., 2021 , 50 , 4514

38. J.D. Chai, Phys. Chem. Chem. Phys., 2008, 10(44), 6615-6620.

39. M. Cossi, G. Scalmani, V. Barone, J. Comput. Chem., 2003, 24(6), 669-681.

40. https://www.chemcomp.com/index.htm

41. S. Lakhera, K. Devlal, A. Ghosh, P. Chowdhury, M. Rana, Chem. Pap., 2020, 15, 1-18. 